\title{
Sintesis Emulsifier Ester Sukrosa Asam Lemak (FACE) Dari Minyak Jagung Menggunakan $\mathrm{Na}_{2} \mathrm{CO}_{3}$
}

\author{
Ardhita Niken Destiana ${ }^{a}$, Ismiyarto ${ }^{a^{*}}$, Ngadiwiyana ${ }^{a}$ \\ a Organic Chemistry Laboratory, Chemistry Department, Faculty of Sciences and Mathematics, Diponegoro University, Jalan Prof. \\ Soedarto, Tembalang, Semarang 50275 \\ * Corresponding author: ismiyarto@live.undip.ac.id
}

\begin{tabular}{|c|c|}
\hline Article Info & Abstract \\
\hline & A synthesis of fatty acid sucrose ester (FACE) emulsifiers from corn oil using $\mathrm{Na}_{2} \mathrm{CO}_{3}$ has \\
\hline $\begin{array}{l}\text { Keywords: } \\
\text { Corn oil, } \\
\text { transesterification } \\
\text { reaction, sucrose } \\
\text { fatty acid ester, } \\
\text { emulsifier }\end{array}$ & $\begin{array}{l}\text { been conducted. The FACE synthesis was performed by refluxing method using fatty acid } \\
\text { methyl ester (FAME), sucrose, methanol solvent and } \mathrm{Na}_{2} \mathrm{CO}_{3} \text { catalyst with variation of } \\
\text { catalyst weight ratio to FAME were } 1.5 \%, 3 \%, 4.5 \%, 6 \% \text { and } 7.5 \% \text {. The FACE optimum } \\
\text { condition occurred in the } \mathrm{Na}_{2} \mathrm{CO}_{3} \text { weight ratio of } 6 \% \text { with degree of transesterification } \\
\text { was } 1,169 \text { and emulsion time of } 347.47 \mathrm{sec} \text {. The GC-MS analysis result on FAME showed } \\
\text { the composition of major compound of FAME was linoleic acid methyl ester, oleic acid } \\
\text { methyl ester, palmitic acid methyl ester and methyl ester of stearic acid. The amount of } \\
\text { catalysts affected the resulting FACE }\end{array}$ \\
\hline
\end{tabular}

Abstrak

Telah dilakukan penelitian sintesis emulsifier ester sukrosa asam lemak (FACE) dari minyak jagung menggunakan $\mathrm{Na}_{2} \mathrm{CO}_{3}$. Sintesis FACE dilakukan dengan metode refluks menggunakan metil ester asam lemak (FAME), sukrosa, pelarut metanol, dan katalis $\mathrm{Na}_{2} \mathrm{CO}_{3}$ dengan variasi rasio berat katalis terhadap FAME 1,5\%, 3\%, 4,5\%, 6\%, dan 7,5\%. Kondisi optimum FACE terjadi pada FACE dengan rasio berat $\mathrm{Na}_{2} \mathrm{CO}_{3} 6 \%$ dengan derajat transesterifikasi 1,169 dan waktu pecah emulsi 347,47 detik. Hasil analisis GC-MS pada FAME menunjukkan komposisi senyawa mayor penyusun FAME adalah metil ester asam linoleat, metil ester asam oleat, metil ester asam palmitat, dan metil ester asam stearat. Banyaknya katalis mempengaruhi FACE yang dihasilkan.

\section{Pendahuluan}

Tanaman jagung (Zea mays L) di Indonesia merupakan tanaman pangan yang penting setelah padi dan terdapat hampir di seluruh kepulauan Indonesia [1]. Dewasa ini, proporsi penggunaan jagung sebagai bahan pangan cenderung menurun, tetapi meningkat sebagai pakan ternak dan bahan baku industri, salah satunya minyak jagung [2].

Minyak jagung diperoleh dengan jalan mengekstrak bagian lembaga. Sistem ekstraksi yang digunakan biasanya sistem press (pressing) atau kombinasi sistem press dan ekstraksi (pressing and solvent extraction). Minyak jagung merupakan trigliserida yang disusun oleh gliserol dan asam-asam lemak. Persentase trigliserida sekitar 98,6\%, sedangkan sisanya merupakan bahan non minyak, seperti abu, zat warna atau lilin. Asam lemak yang menyusun minyak jagung terdiri dari asam lemak jenuh dan asam lemak tak jenuh. Jumlah asam lemak jenuh dalam minyak jagung sekitar $13 \%$, yaitu $10 \%$ asam palmitat dan $3 \%$ asam stearat. Sedangkan golongan asam lemak tak jenuh yang menyusun trigliserida minyak jagung sekitar $86 \%$ yang terdiri dari $30 \%$ asam oleat dan 56\% asam linoleat [1].

Asam-asam lemak tersebut sangat berpotensi untuk diubah menjadi senyawa metil ester asam lemak (Fatty Acid Methyl Ester (FAME)) yang memiliki banyak peranan dalam berbagai macam industri, misalnya 
biodiesel. FAME dapat digunakan untuk sintesis ester asam lemak karbohidrat (Fatty Acid Carbohydrate Ester (FACE)) yang mempunyai fungsi sebagai emulsifier non ionik dan sebagai bahan baku industri polimer [3].

FAME dari minyak jagung dengan rantai asam lemak yang panjang dapat mengalami transesterifikasi dengan sukrosa sehingga menghasilkan ester asam lemak sukrosa (FACE) yang merupakan senyawa amfifilik, yaitu senyawa yang mempunyai gugus hidrofilik (polar) dan hidrofobik (non polar) sehingga dapat digunakan sebagai emulsifier.

Pada sintesis FACE ini, katalis merupakan faktor yang penting dalam reaksi transesterifikasi FAME menjadi FACE. Katalis basa lebih sering digunakan karena kurang korosif dan lebih efektif dibandingkan dengan katalis asam, di mana katalis basa dapat mengikat ion $\mathrm{H}+$ dari molekul alkohol menghasilkan RO- yang merupakan nukleofil kuat sehingga reaksi transesterifikasi berlangsung lebih cepat. $\mathrm{Na}_{2} \mathrm{CO}_{3}$ dipilih sebagai katalis karena relatif sedikit menghasilkan air, sehingga memungkinkan untuk dilakukan reaksi pada suhu yang tinggi. Banyaknya katalis tersebut berpengaruh terhadap produk yang dihasilkan. Rasio berat katalis $\mathrm{Na}_{2} \mathrm{CO}_{3}$ terhadap FAME pada sintesis FACE menentukan derajat transesterifikasinya. Derajat transesterifikasi ini menunjukkan banyaknya gugus hidroksil $(-\mathrm{OH})$ yang tersubstitusi menjadi gugus ester. Derajat transesterifikasi FACE yang dihasilkan mempengaruhi kestabilannya sebagai emulsi.

\section{Metodologi}

Penentuan Bilangan Asam

Minyak jagung sebanyak 10 gram dimasukkan dalam erlenmeyer $250 \mathrm{~mL}$ lalu ditambahkan campuran alkohol dengan eter 1:1 serta PP, digojog. Kemudian larutan dititrasi dengan $\mathrm{NaOH} 0,1 \mathrm{~N}$ hingga berwarna merah muda. Selanjutnya ditentukan bilangan asamnya untuk mengetahui kadar FFA dalam minyak.

Bilangan asam $=\frac{b \times N \times 40}{a} \times f$

Di mana:

$\mathrm{a}$ = berat sampel minyak jagung $(\mathrm{g})$

$\mathrm{b}=$ volume $\mathrm{NaOH}$ yang digunakan $(\mathrm{mL})$

$\mathrm{f}=$ faktor pengenceran

$\mathrm{N}=$ normalitas $\mathrm{NaOH}=0,1 \mathrm{~N}$

Sintesis Metil Ester Asam Lemak (FAME)

Sebanyak 20 gram minyak jagung dimasukkan ke dalam labu refluks leher tiga dan dipanaskan sampai suhu 500C. Selanjutnya larutan KOH (0,1 gram) dalam metanol $(4,3754$ gram $)$ pada corong penambah dimasukkan ke dalam labu yang berisi minyak dan telah dipanaskan tersebut. Kemudian campuran direfluks selama 45 menit pada suhu $700 \mathrm{C}$ sambil diaduk menggunakan magnetic stirer. Campuran yang diperoleh didiamkan selama 30 menit dan setelah pendiaman selama 30 menit lapisan ester yang terbentuk pada lapisan atas dipisahkan dari gliserol menggunakan corong pisah. Kemudian FAME yang diperoleh dianalisis menggunakan GC-MS.

Sintesis Ester Sukrosa Asam Lemak (FACE) dari FAME

Pada tahap ini, sintesis ester asam lemak sukrosa dilakukan dengan memasukkan 3,625 gram sukrosa, 5,2 gram FAME, $\mathrm{Na}_{2} \mathrm{CO}_{3}$, dan pelarut metanol ke dalam labu leher tiga yang telah dirangkai dengan kondensor, termometer, pengaduk magnet, dan pemanas. Selanjutnya campuran diaduk dengan magnetic stirer selama 2 jam. Campuran direfluks pada suhu $600 \mathrm{C}$ dengan variasi berat $\mathrm{Na}_{2} \mathrm{CO}_{3}$. FACE yang dihasilkan disaring dengan corong Buchner dan hasil yang diperoleh dianalisis struktur kimianya menggunakan spektrofotometer FTIR yang selanjutnya digunakan untuk menghitung derajat transesterifikasinya. Setelah itu, diuji stabilitasnya sebagai emulsifier. Proses dilakukan untuk persen berat $\mathrm{Na}_{2} \mathrm{CO}_{3}$ terhadap FAME $1,5 \% ; 3 \% ; 4,5 \% ; 6 \%$ dan $7,5 \%$.

$$
\text { Derajat Transesterifikasi } \frac{A_{C=O}}{A_{O-H}} \rightarrow A=-\log \frac{I}{I_{o}}
$$

Uji Stabilitas FACE Sebagai Emulsifier

Uji stabilitas emulsifier dilakukan dengan membuat sistem emulsi minyak-FACE-akuades dengan perbandingan tertentu, sebanyak 2 gram minyak jagung ditambah 0,5 gram FACE (ester sukrosa) dan dilakukan pengocokan yang dilanjutkan titrasi dengan aquades hingga terbentuk emulsi dan ditentukan waktunya hingga emulsi pecah. Sistem emulsi dibuat dengan menggunakan FACE dengan variasi berat $\mathrm{Na}_{2} \mathrm{CO}_{3}$ yang sudah ditentukan.

\section{Hasil Dan Pembahasan}

\section{Penentuan Bilangan Asam}

Bilangan asam merupakan banyaknya milligram basa kuat yang dibutuhkan untuk menetralkan asam lemak bebas yang terdapat dalam 1 gram minyak. Prinsip dari bilangan asam adalah penguraian asam lemak bebas menjadi garam asam lemak dan airnya. Penentuan bilangan asam bertujuan untuk mengetahui kadar asam lemak bebas dalam minyak. Setelah dilakukan penentuan bilangan asam diperoleh bilangan asam minyak jagung tersebut sebesar 0,173296. Minyak ini masih merupakan campuran antara trigliserida dan asam lemak bebas. Bilangan asam sebesar 0,173296 menunjukan bahwa kadar asam lemak bebas pada minyak sudah rendah. Jika kadar asam lemak bebasnya masih tinggi, maka perlu diturunkan terlebih dahulu karena asam lemak bebas tersebut dapat bereaksi dengan $\mathrm{KOH}$ membentuk sabun sehingga dapat mempengaruhi proses transesterifikasi. Reaksi saponifikasi mengakibatkan penurunan jumlah $\mathrm{KOH}$ sehingga akan mengurangi efektifitasnya sebagai katalis [3].

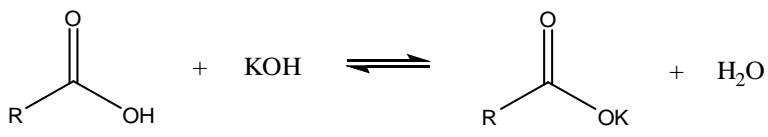

Gambar 1. Reaksi Saponifikasi Asam Lemak 


\section{Sintesis Metil Ester Asam Lemak (FAME)}

Sintesis senyawa metil ester asam lemak (FAME) dilakukan dengan mereaksikan trigliserida (minyak) dengan metanol menggunakan katalis $\mathrm{KOH}$.

Tahap-tahap reaksi yang terjadi ditunjukkan pada Gambar 2.

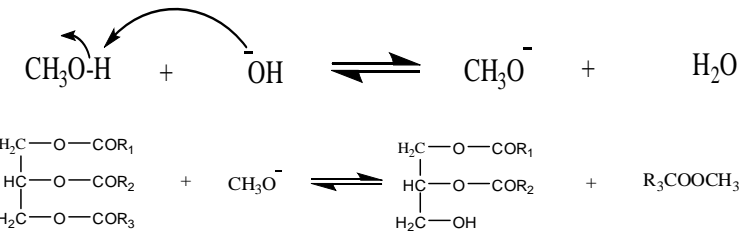

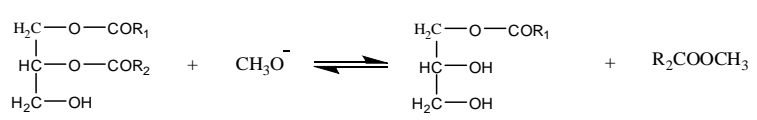

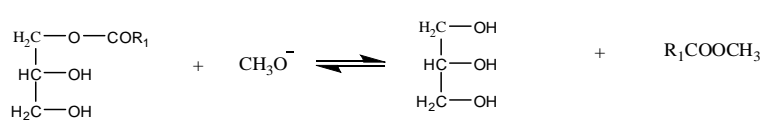

Gambar 2. Tahap-Tahap Reaksi Transesterifikasi Pada Sintesis FAME

Pencampuran katalis KOH dengan metanol akan menyebabkan $\mathrm{KOH}$ mengalami ionisasi menjadi $\mathrm{K}+$ dan $\mathrm{OH}-$, kemudian ion $\mathrm{OH}-$ akan mengikat $\mathrm{H}+$ pada metanol sehingga akan menghasilkan ion metoksida (CH3O-) yang merupakan nukleofil yang lebih kuat dibandingkan metanol. Ion $\mathrm{CH} 3 \mathrm{O}-$ tersebut akan menyerang gugus karbonil pada trigliserida menghasilkan metil ester asam lemak dan digliserida. Digliserida ini kemudian akan mengalami reaksi dengan metoksida yang lain membentuk metil ester asam lemak dan monogliserida. Kemudian monogliserida ini akan mengalami siklus katalitik yang sama membentuk metil ester dan gliserol.

Proses transesterifikasi menghasilkan dua fasa yang tidak saling bercampur. Fasa atas yang berwarna kuning muda merupakan FAME, sedangkan fasa bawah terdiri dari gliserol, katalis $\mathrm{KOH}$ dan metanol sisa yang berwarna kuning tua. Metil ester asam lemak (FAME) yang diperoleh dari 20,0079 g minyak jagung adalah sebesar 20,5771 g.

FAME tersebut kemudian dianalisis dengan GC-MS. Analisis ini bertujuan untuk mengetahui komposisi senyawa yang terdapat pada FAME dari minyak jagung ini. Hasil analisis GC-MS dari FAME ditampilkan pada Gambar 3.

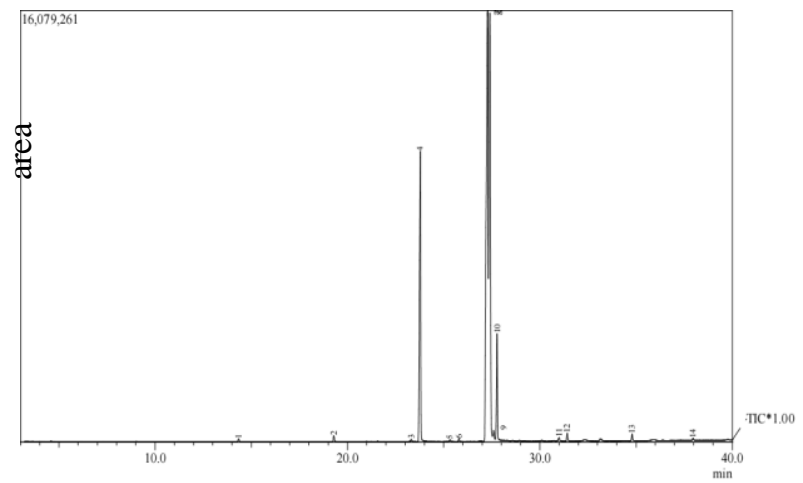

Gambar 3. Kromatogram FAME dari Minyak Jagung

Dari gambar di atas terlihat adanya 14 puncak yang berarti terdapat 14 senyawa yang berbeda dengan empat puncak utamanya adalah puncak nomor 4, 7, 8 dan 10. Data keempat puncak tersebut ditampilkan pada tabel 1.

Tabel 1. Analisis FAME dengan GC-MS

\begin{tabular}{ccccc}
\hline Puncak & $\begin{array}{c}\text { Waktu retensi } \\
(\text { menit })\end{array}$ & $\begin{array}{c}\text { Kelimpahan } \\
(\%)\end{array}$ & $\begin{array}{c}\text { Massa molekul } \\
(\mathrm{g} / \mathrm{mol})\end{array}$ & Metil ester \\
\hline 4 & 23,786 & 17,79 & 270 & $\begin{array}{c}\text { Asam } \\
\text { palmitat }\end{array}$ \\
7 & 27,289 & 42,70 & 294 & $\begin{array}{c}\text { Asam } \\
\text { linoleat }\end{array}$ \\
8 & 27,398 & 31,80 & 296 & $\begin{array}{c}\text { Asam oleat } \\
\text { Asam } \\
\text { stearat }\end{array}$ \\
\hline
\end{tabular}

Dari tabel tersebut dapat diketahui bahwa kandungan metil ester terbanyak dalam FAME adalah metil ester asam linoleat dengan kelimpahan 42,70\%.

Sintesis Ester Sukrosa Asam Lemak (FACE) dari FAME

Sintesis ester asam lemak sukrosa (FACE) dilakukan dengan mereaksikan FAME dengan sukrosa menggunakan katalis $\mathrm{Na}_{2} \mathrm{CO}_{3}$ pada temperatur $60^{\circ} \mathrm{C}$ selama 2 jam. Penggunaan katalis $\mathrm{Na}_{2} \mathrm{CO}_{3}$ mempertimbangkan terbentuknya bikarbonat sehingga tidak terbentuk air dan ester tak terhidrolisis [4](Adamopoulos, 2006). Pada sintesis FACE ini dilakukan lima variasi rasio berat $\mathrm{Na}_{2} \mathrm{CO}_{3}$ terhadap berat FAME yaitu $1,5 \% ; 3 \% ; 4,5 \% ; 6 \%$ dan $7,5 \%$. Hasil yang diperoleh yaitu berupa padatan berwarna putih, sedangkan berat dan titik leleh masing-masing variasi FACE yang dihasilkan ditunjukkan pada tabel 2. berikut.

Tabel 2. Hasil Optimasi Sintesis FACE

\begin{tabular}{ccc}
\hline $\begin{array}{c}\text { Berat } \mathrm{Na}_{2} \mathrm{CO}_{3} \\
(\% \mathrm{~b} / \mathrm{b})\end{array}$ & $\begin{array}{c}\text { Berat Produk } \\
(\mathrm{g})\end{array}$ & $\begin{array}{c}\text { Titik Leleh } \\
\left({ }^{\circ} \mathrm{C}\right)\end{array}$ \\
\hline 1,5 & 3,6661 & $184-186$ \\
3 & 3,6960 & $188-189$ \\
4,5 & 2,0480 & $189-190$ \\
6 & 3,0676 & $188-189$ \\
7,5 & 3,6532 & $183-184$ \\
\hline
\end{tabular}

Mekanisme reaksi transesterifikasi yang terjadi pada sintesis FACE ditunjukkan pada Gambar 4. berikut.

$\mathrm{CH}_{3} \mathrm{OH}+\mathrm{Na}_{2} \mathrm{CO}_{3} \rightleftharpoons \mathrm{CH}_{3} \mathrm{O}^{-}+\mathrm{Na}^{+}+\mathrm{NaHCO}_{3}$ 


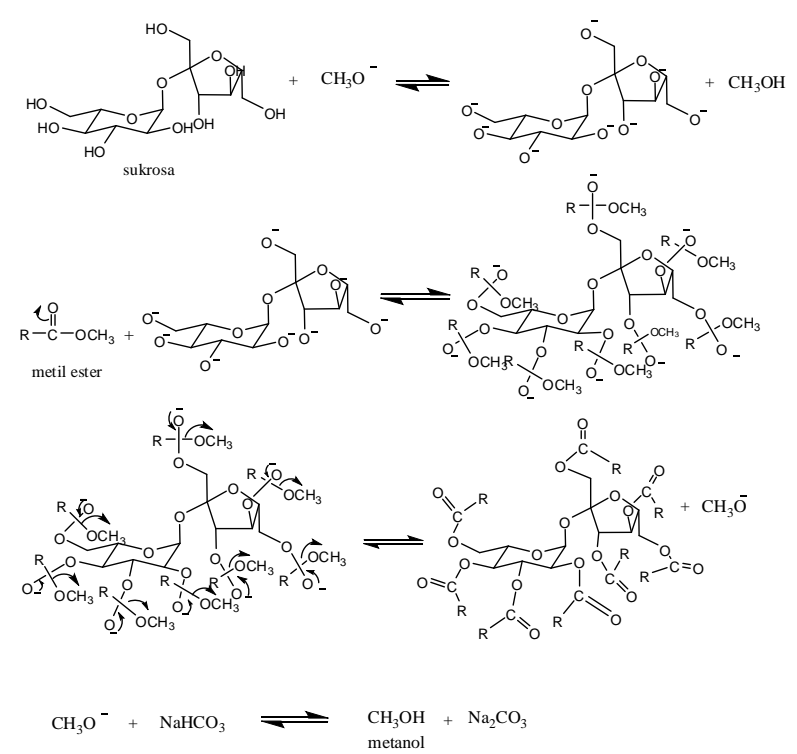

Gambar 4. Tahap-Tahap Reaksi Transesterifikasi Pada Sintesis FACE

Pada reaksi di atas, tahap pertama adalah reaksi katalis $\mathrm{Na}_{2} \mathrm{CO}_{3}$ dengan pelarut metanol menghasilkan ion metoksida yang akan menyerang gugus hidroksil dari sukrosa menghasilkan suatu alkoksida dan metanol, kemudian alkoksida akan menyerang gugus karbonil dari metil ester. Serangan ini menghasilkan suatu intermediet tetrahedral yang akan mengalami penataan ulang (resonansi) menghasilkan ester sukrosa asam lemak (FACE) dan ion metoksida. Tahap terakhir adalah protonasi katalis yang menghasilkan suatu spesies aktif akan bereaksi dengan ion metoksida menghasilkan kembali katalis dan metanol.

Karakteristik struktur kimia dari FACE dilakukan dengan menggunakan spektrofotometer FTIR. Analisis FTIR dilakukan untuk mengetahui perbedaan serapan pada gugus hidroksil dan karbonil sebelum dan setelah transesterifikasi. Hal ini menandakan keberhasilan proses transesterifikasi yang telah dilakukan.

Karakter sukrosa adalah keberadaan serapan hidroksil yang kuat, sementara FACE adalah keberadaan serapan karbonil pada sekitar daerah $1700 \mathrm{~cm}^{-1}$ dan C-O ester pada sekitar daerah $1100 \mathrm{~cm}^{-1}$ [4].

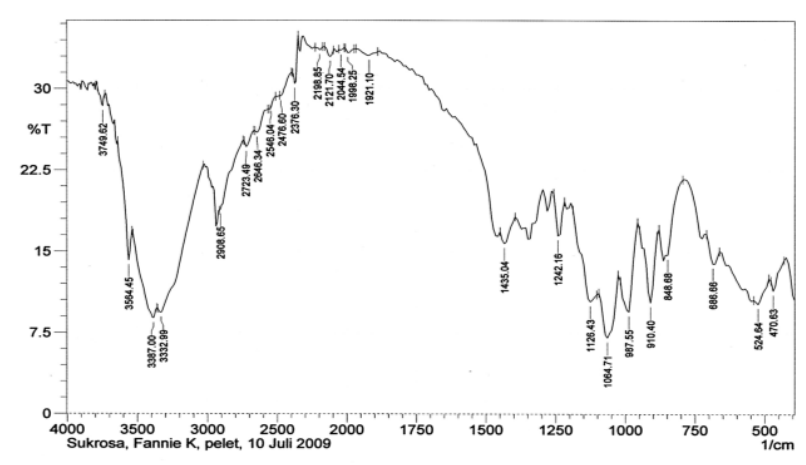

Gambar 5. Spektra FTIR Sukrosa
Tabel 3. Daerah Serapan FTIR Sukrosa

\begin{tabular}{ccc}
\hline No. & Gugus & Bilangan Gelombang $\left(\mathrm{cm}^{-1}\right)$ \\
\hline 1 & $\mathrm{O}-\mathrm{H}$ & 3387 \\
2 & $\mathrm{C}(\mathrm{SP} 3)-\mathrm{H}$ & 2908,65 \\
3 & $\mathrm{C}-\mathrm{O}$ & 1126,43 \\
\hline
\end{tabular}

Setelah dilakukan analisis FTIR, diketahui bahwa pada FACE $1,5 \%$, 3\%, 4,5\%, $6 \%$ maupun $7,5 \%$ muncul gugus karbonil $(\mathrm{C}=\mathrm{O})$ yang ditunjukkan pada puncak $1743,65 \mathrm{~cm}^{-1}$ dan diperkuat dengan adanya gugus $\mathrm{C}-\mathrm{O}$ ester pada sekitar daerah $1100 \mathrm{~cm}^{-1}$. Hal ini menandakan terbentuknya FACE. Selain itu, pada FACE yang dihasilkan tersebut juga masih terdapat gugus $-\mathrm{OH}$.

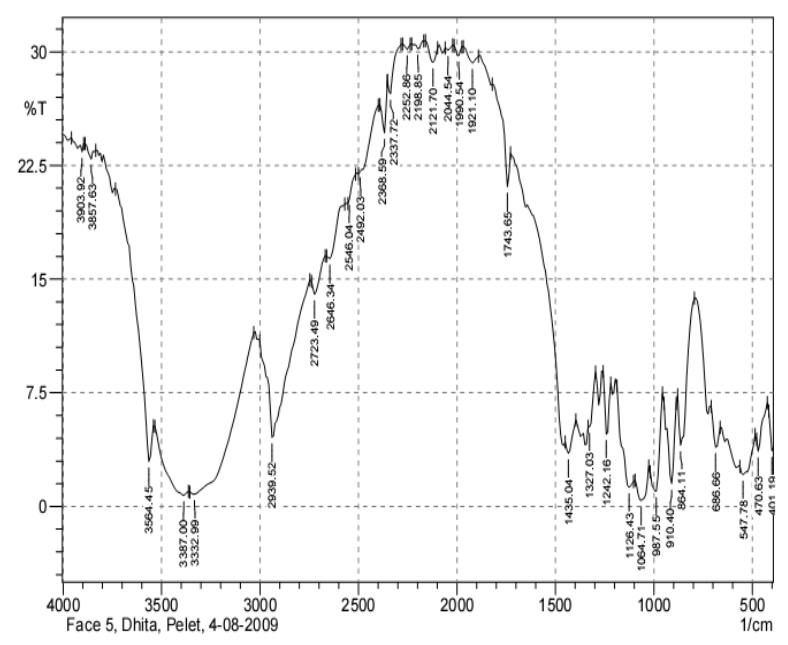

Gambar 6. Spektra FTIR FACE

Tabel 4. Daerah Serapan FTIR FACE

\begin{tabular}{cccccc}
\hline \multirow{2}{*}{$\begin{array}{c}\text { Gugus } \\
\text { Fungsi }\end{array}$} & \multicolumn{5}{c}{ Bilangan gelombang pada FACE dengan rasio berat $\mathrm{Na}_{2} \mathrm{CO}_{3}$} \\
\cline { 2 - 6 }$\left(\mathrm{cm}^{-1}\right)$
\end{tabular}

Hasil yang diperoleh menunjukkan bahwa FACE dapat dibuat melalui reaksi transesterifikasi antara FAME dengan sukrosa menggunakan katalis $\mathrm{Na}_{2} \mathrm{CO}_{3}$. Derajat transesterifikasi yang diperoleh dari spektra FTIR FACE tersebut sebesar 0,665 untuk $\mathrm{Na}_{2} \mathrm{CO}_{3} 1,5 \%$; 0,722 untuk $\mathrm{Na}_{2} \mathrm{CO}_{3} 3 \% ; 0,754$ untuk $\mathrm{Na}_{2} \mathrm{CO}_{3} 4,5 \% ; 1,169$ untuk $\mathrm{Na}_{2} \mathrm{CO}_{3} 6 \%$; dan 0,317 untuk $\mathrm{Na}_{2} \mathrm{CO}_{3} 7,5 \%$. Derajat transesterifikasi ini menunjukkan banyaknya gugus O$\mathrm{H}$ yang tersubstitusi oleh ester. Semakin besar nilai derajat transesterifikasi maka semakin banyak gugus $\mathrm{O}-\mathrm{H}$ yang telah tersubstitusi menjadi gugus ester.

\section{Uji Stabilitas FACE Sebagai Emulsifier}

Kestabilan emulsi minyak dalam air dengan ester asam lemak sukrosa (FACE) sebagai emulsifier dapat diketahui dengan menentukan waktu dari saat emulsi terbentuk sampai emulsi pecah kembali, di mana semakin besar waktu pecah emulsi menunjukkan bahwa emulsi tersebut semakin stabil. Waktu pecah emulsi ditunjukkan pada tabel di bawah. 
Tabel 5. Waktu Pecah Emulsi

\begin{tabular}{ccc}
\hline $\begin{array}{c}\text { FACE }(\% \\
\left.\mathrm{Na}_{2} \mathrm{CO}_{3}\right)\end{array}$ & $\begin{array}{c}\text { Derajat } \\
\text { Transesterifikasi }\end{array}$ & $\begin{array}{c}\text { Waktu Pecah } \\
\text { (detik) }\end{array}$ \\
\hline 1,5 & 0,665 & 261,83 \\
3 & 0,722 & 306,61 \\
4,5 & 0,754 & 317,38 \\
6 & 1,169 & 347,47 \\
7,5 & 0,317 & 139,27 \\
\hline
\end{tabular}

Tabel di atas menunjukkan bahwa semakin besar rasio berat $\mathrm{Na}_{2} \mathrm{CO}_{3}$ pada FACE maka semakin stabil emulsi yang terbentuk dan emulsi dengan stabilitas tertinggi dihasilkan oleh FACE dengan rasio berat $\mathrm{Na}_{2} \mathrm{CO}_{3}$ $6 \%$. Ini menunjukkan bahwa dengan derajat transesterifikasi yang semakin besar maka kestabilan emulsi juga semakin tinggi dan semakin banyak gugus -OH yang tersubstitusi menjadi gugus ester sehingga gaya tarik antara gugus hidrofobik dengan minyak semakin kuat. Hal ini yang menyebabkan semakin stabilnya sistem emulsi.

\section{Kesimpulan}

Dari penelitian yang telah dilakukan dapat diambil kesimpulan sebagai berikut:

Ester sukrosa asam lemak (FACE) dapat disintesis dari minyak jagung dengan menggunakan katalis $\mathrm{Na}_{2} \mathrm{CO}_{3}$ dan dapat dimanfaatkan sebagai emulsifier.

Hasil penelitian ini menunjukkan bahwa kondisi optimum kestabilan emulsi diperoleh pada FACE dengan rasio berat $\mathrm{Na}_{2} \mathrm{CO}_{3} 6 \%$ dengan waktu pecah emulsi 347,47 detik dan derajat transesterifikasi 1,169.

\section{Daftar Pustaka}

[1] S. Ketaren, Pengantar Teknologi Minyak dan Lemak Pangan, in, Universitas Indonesia Press, Jakarta, 1986.

[2] Suarni, Muh Yasin, Jagung sebagai Sumber Pangan Fungsional, Iptek Tanaman Pangan, 6, 1, (2015) 4156

[3] Ulf Schuchardt, Ricardo Sercheli, Rogério Matheus Vargas, Transesterification of vegetable oils: a review, Journal of the Brazilian Chemical Society, 9, 3, (1998) 199-210 http://dx.doi.org/10.1590/S010350531998000300002

[4] Lambrini Adamopoulos, Understanding the formation of sugar fatty acid esters, in: Wood and Paper Science, North Carolina State University, North Carolina, 2006, pp. 116. 